\title{
Cigarette smoking and multiple sclerosis (MS): Yet another reason to quit
}

Robin L. Brey, MD

\section{What is MS?}

MS is a chronic neurologic disorder of young adults. Inflammation in the nervous system leads to damage to nerves and myelin (covering of the nerves) in the central nervous system (brain and spinal cord). More information about MS can be found on the next page.

\section{What causes MS?}

Even after many years of being studied, the cause of MS is still unknown. It is believed that the disease is probably triggered by a combination of factors that are inherited and are present in the environment. The most likely environmental factor seems to be a virus or other source of infection. However, a specific infection has not yet been identified. In this issue of Neurology, Riise and colleagues (2003;61:1122-1124) study another common environmental factor that may play a role in triggering MS: cigarette smoking. An editorial by Franklin and Nelson $(2003 ; 61: 1032-1034)$ puts these findings into perspective.

\section{Cigarette smoking and the risk for MS}

These researchers studied the relationship between cigarette smoking and the risk for developing MS in 22,312 people between the ages of 40 and 47 living in Hordaland, Norway. Information was gathered by using questionnaires and a physical examination. Detailed information about smoking included current and previous smoking history and the age smoking started.

There were 87 people who reported having MS. All patients with MS who were current smokers and most who had smoked in the past had started smoking before they developed MS. Most people started smoking about 15 years before they developed MS. The risk for developing MS was nearly twice as high in people who currently smoked or had ever smoked than in nonsmokers. When men and women were evaluated separately, the risk for developing MS was nearly three times greater for men and one and a half times greater for women who smoked than in nonsmokers. Smoking also increased the risk for heart attacks, angina, and asthma for both men and women.

\section{How could smoking increase the risk for MS?}

Smoking causes damage to the cells that form the lining of blood vessels. When these cells, called endothelial cells, are damaged, a number of things can happen. The immune system normally fights off bad agents like bacteria and viruses. When endothelial cells are damaged the immune system can become overactive and turn against the cells of our own bodies. This is called autoimmune disease, and MS is an autoimmune disease. Endothelial cells form a very tight barrier in the brain blood vessels to prevent toxic substances from entering the brain. If endothelial cells are damaged, the brain blood vessels may become leaky. Toxic substances may pass into the brain and cause damage. These are all theories that need to be tested in the future.

\section{What does all this mean to me?}

The Surgeon General has been warning everyone for years that smoking cigarettes may be hazardous to our health. Smoking increases the risk for cancer, heart and lung disease, and stroke. MS may be added to that list. How many reasons does a person need to quit smoking? The evidence is obviously mounting. 


\section{About multiple sclerosis}

MS is a disabling neurologic disorder of young adults, affecting at least 300,000 Americans. The average age at diagnosis is 30, typically starting between the ages of 15 and 50. Women are affected at least twice as often as men. It is more common in persons of northern European heritage and those living furthest from the equator.

\section{MS involves inflammation within} the central nervous system (the brain and spinal cord), followed by the loss of the protective myelin sheaths that surround nerve fibers. When the myelin is damaged, nerve impulses are not quickly and efficiently transmitted. Besides damage to the myelin sheaths, it is now recognized that the nerve fibers, called axons, also are damaged in MS to varying extent. Lesions (called plaques) develop in the brain and spinal cord and can cause the symptoms of MS listed below.

\section{What are the symptoms?}

There are several types of MS. Most people with MS begin with relapsing-remitting disease. This means that the symptoms come and go, often leaving the person feeling nearly normal until another relapse, or MS attack, occurs. Symptoms associated with relapses usually develop over a period of days. The problems can last for a matter of days or weeks and then go away, sometimes even without any treatment. New attacks occur at irregular intervals, usually one attack every 1 to 2 years. Common symptoms include:

- Vision loss

- Numbness or tingling

- Weakness or fatigue

- Unsteadiness in walking

- Double vision

- Heat intolerance

- Partial or complete paralysis

- Electric shock sensations when bending the neck
About $50 \%$ of patients with relapsing-remitting MS develop a progressive form of MS, called secondary progressive MS, in which there is continual worsening. In this phase of the disease, patients may continue to have relapses or may stop having them altogether. About $15 \%$ of patients have progressive worsening from the beginning of their MS and do not experience relapses of MS. This form of MS is called primary progressive MS.

\section{How is MS diagnosed?}

The diagnosis of MS is based on a history of multiple attacks over time of neurologic lesions that affect different parts of the central nervous system. Your neurologist will order tests that will help confirm the diagnosis. Usually a magnetic resonance imaging (MRI) scan of the brain (and possibly the spinal cord) is ordered to find evidence of abnormal areas. Lumbar puncture (spinal tap) is also helpful to detect specific problems with the cerebrospinal fluid.

\section{What causes MS?}

The cause of MS is unknown. There is strong evidence that MS is immune mediated. This means that the person's own immune system attacks the central nervous system (an autoimmune disease).

\section{What are the treatments?}

Currently, there is no prevention or cure for MS. However, this is a promising time for people with MS, as several new medications that affect the underlying disease process have been approved or are awaiting approval by the US Food and Drug Administration (FDA). You should ask your neurologist about the best treatment options for you. Current treatments are divided into three categories:

Medications that treat the symptoms of MS. These include medica- tions to treat depression, decrease muscle stiffness, reduce fatigue, control bladder symptoms, reduce pain, and address sexual dysfunction.

Medications that modify attacks when they occur. These are primarily corticosteroids (a synthesized adrenal hormone) that can shorten an attack.

\section{Medications that modify disease} activity. These are taken on a regular basis to help reduce the frequency of attacks and the longterm damage to brain caused by MS. Disease-modifying therapies currently FDA-approved for treating MS include recombinant

$\beta$-interferons (Avonex, Betaseron, and Rebif), glatiramer acetate (Copaxone), and an immunosuppressant/ chemotherapy drug, mitoxantrone (Novantrone).

\section{For more information:}

National Multiple Sclerosis Society

733 Third Avenue

New York, NY 10017

800-FIGHT-MS

http://www.nmss.org

Multiple Sclerosis Association of America 601 White Horse Pike Oaklyn, NJ 08107

800-333-4MSA

http://www.msaa.com

American Academy of Neurology 1080 Montreal Avenue

St. Paul, MN 55116

Tel: 800-879-1960

Fax: 651-695-2791

http://www.aan.com

American Academy of Neurology Education \& Research Foundation 1080 Montreal Avenue St. Paul, MN 55116 651-695-2712

http://www.foundation@aan.com http://www.thebrainmatters.org 


\section{Neurology}

\section{Cigarette smoking and multiple sclerosis (MS): Yet another reason to quit Robin L. Brey \\ Neurology 2003;61;E11-E12 \\ DOI 10.1212/WNL.61.8.E11}

\section{This information is current as of October 27, 2003}

\section{Updated Information \&} Services

Citations

Permissions \& Licensing

Reprints including high resolution figures, can be found at: http://n.neurology.org/content/61/8/E11.full

This article has been cited by 1 HighWire-hosted articles: http://n.neurology.org/content/61/8/E11.full\#\#otherarticles

Information about reproducing this article in parts (figures,tables) or in its entirety can be found online at:

http://www.neurology.org/about/about_the_journal\#permissions

Information about ordering reprints can be found online: http://n.neurology.org/subscribers/advertise

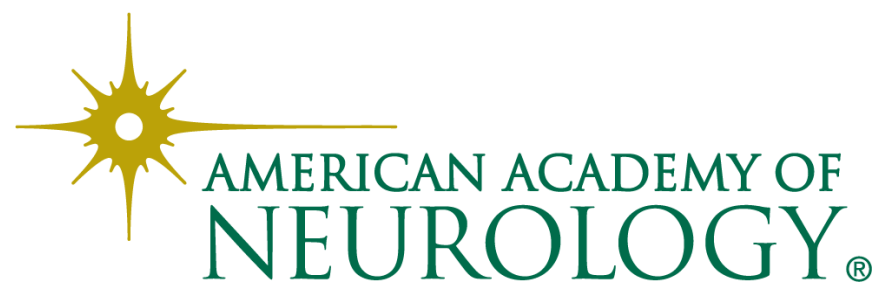

